\title{
Perilaku Sehat Pelaku Olahraga Tai Chi
}

\author{
Jeffri Yulianto \\ Margaretha Sih Setija Utami \\ jeffriyulianto94@gmail.com \\ cicih@unika.ac.id \\ Fakultas Psikologi \\ Universitas Katolik Soegijapranata
}

\begin{abstract}
The purpose of this study is to describe the health behavior of people who doing Tai Chi, in order to capture psychological dynamics start from the background why people doing Tai Chi, up to appearance the health behavior for that person. The qualitative methd is used in this study, while interview and observation are used to collect the data. Subjects in this study amounted to three people who have been doing Tai Chi sports for at least three years on a regular basis and domiciled in the city of Semarang. Based on research conducted by researchers, Tai Chi sporters have a healthy behavior diverse. Healthy behaviors raised by research subjects include diet, rest patterns, exercise, stress management, compliance with traffic rules, and not consuming cigarettes, alcoholic beverages and illegal drugs.
\end{abstract}

Keywords : health behavior, Tai Chi 


\section{PENDAHULUAN}

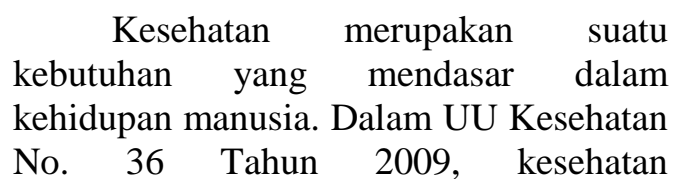
didefinisikan sebagai keadaan sehat, baik secara fisik, mental, spritual maupun sosial yang memungkinkan setiap orang untuk hidup produktif secara sosial dan ekonomis. Tidak hanya terbebas dari gangguan fisik, mental, dan sosial, tetapi kesehatan dipandang sebagai alat bagi seseorang untuk lebih produktif. Penelitian Rokeach (Ekowarni, 2001, h.1), menghasilkan kesimpulan bahwa kesehatan menduduki posisi pertama pada urutan hal-hal yang dianggap bernilai dalam kehidupan manusia. Kesehatan bukan hanya berkaitan dengan penyakit tetapi mempunyai dimensi yang lebih luas, yaitu selain dimensi fisik (biologis), juga berkaitan dengan dimensi mental (perilaku) dan sosial (lingkungan) yang keseluruhannya saling memengaruhi (Ekowarni, 2001, h.1).

Kemajuan era globalisasi mengubah cara pandang manusia dan melahirkan kebiasaan-kebiasaan baru yang tidak sesuai dengan perilaku sehat. Perilaku sehat yang buruk memiliki efek yang buruk bagi kesehatan atau menimbulkan penyakit. Perilaku merokok, mengkonsumsi alkohol, mengkonsumsi makan makanan yang berlemak tinggi, pola tidur yang tidak teratur adalah bentuk perilaku perilaku yang tidak sehat. Perilaku yang tidak sehat berpengaruh pada meningkatnya penyakit kronis seperti diabetes, kanker, dan hepatitis.

Kondisi global berdasarkan data WHO menunjukkan bahwa dari 57 juta kematian yang terjadi di dunia pada tahun 2008, sebanyak 36 juta atau hampir dua pertiganya disebabkan oleh penyakit tidak menular (penyakit kronis). Di negaranegara dengan tingkat ekonomi rendah dan menengah, dari seluruh kematian yang terjadi pada orang-orang berusia kurang dari 60 tahun, 29\% disebabkan oleh penyakit tidak menular, sedangkan di negara-negara maju menyebabkan 13\% kematian. Proporsi penyebab kematian penyakit tidak menular pada orang-orang berusia kurang dari 60 tahun meliputi: gangguan kardiovaskular merupakan penyebab terbesar (39\%), diikuti kanker (27\%), sedangkan penyakit pernafasan kronis, penyakit pencernaan dan penyakit tidak menular yang lain bersama-sama menyebabkan sekitar 30\% kematian, serta 4\% kematian disebabkan diabetes mellitus (WHO, 2014).

Obesitas juga menjadi salah satu gangguan kesehatan yang muncul pada penduduk di Indonesia. Obesitas merupakan kondisi di mana lemak yang ada di dalam tubuh berada pada jumlah yang berlebihan dan obesitas ini tergolong dalam penyakit kronik yang dapat diatasi (Kompas, 2010). Obesitas muncul lebih karena gaya hidup yang tidak sehat, bisa dikarenakan pola makan yang tidak sehat. Data dari Kementerian Kesehatan RI tahun 2013 menunjukkan bahwa presentase obesitas sentral pada penduduk di Indonesia mengalami peningkatan hingga yang tertinggi pada usia 45-54 tahun dengan angka 26,1\% (Kemenkes RI, 2013, h.11). Hal ini menunjukkan bahwa pada usia 45 sampai 54 tahun mengalami kondisi gangguan kesehatan obesitas yang paling tinggi. Selain obesitas, merokok juga menjadi salah satu kebiasaan tidak sehat yang dimiliki oleh sebagaian besar penduduk di Indonesia. Data Kementerian Kesehatan RI tahun 2013 menunjukkan bahwa prevalensi merokok pada lansia dari usia 55 tahun hingga 75 tahun ke atas memiliki presentase di atas 30 persen, dan yang tertinggi di usia 45-54 tahun yaitu 38 $\%$ (Kemenkes RI, 2013, h.12). 
$\begin{array}{cccr}\text { Perilaku yang tidak sehat } & \text { tak } \\ \text { memunculkan } & \text { banyak permasalahan }\end{array}$ kesehatan baik pada remaja maupun orang dewasa. Upaya untuk menjaga kesehatan dapat dilakukan dengan pola hidup sehat salah satunya adalah dengan berolahraga. Menurut Sarafino (Rahmadian, 2011, h.17), semua aktifitas fisik kecuali fidgeting (gerak tubuh yang disebabkan oleh rasa gelisah atau gugup) merupakan kegiatan yang menggunakan energi dan pembakaran kalori. Olahraga adalah kelas khusus aktifitas fisik di mana orang menggunakan tubuh mereka demi kesehatan dan pengembangan tubuh.

Jenis olahraga yang cukup populer di Indonesia adalah seni beli diri. Seni bela diri yang terkenal di dunia adalah seni bela diri dari Cina, yang termasuk di dalamnya adalah $\mathrm{Wu}$ Shu, Wing Chun, dan Tai Chi. Wu Shu dan Wing Chun merupakan seni bela diri yang melatih kekuatan otot dan pertahanan diri dalam bentuk bergulat dan bertarung. Sedangkan olahraga Tai Chi adalah seni bela diri yang dipraktekkan dalam bentuk pertahana diri dan menjaga kesehatan. Tai Chi juga melatih manajemen stres dan memperoleh umur yang panjang. Tai Chi adalah seni bela diri yang paling berkaitan dengan psikologis. Dibandingkan dengan Wing Chun, Tai Chi lebih terkenal dan memiliki lebih banyak jumlah pengikut di seluruh dunia (Arora, 2015). Salah satu organisasi yang mengadakan pelatihan Tai Chi dan membuka kelas Tai Chi di berbagai negara adalah Tai Chi Foundation (TCF). Organisasi ini membuka kelas pelatihan Tai Chi di beberapa negara di Amerika dan Eropa.

Tai Chi tidak hanya memiliki manfaat yang baik bagi kesehatan manusia, tetapi juga dapat membentuk perilaku dan kebiasaan sehat bagi orang yang melakukannya dengan benar. Pusat daerah tegmental ventral (VTA), otak tengah dekat hippocampus, menghasilkan dopamin yang terhubung dengan sinyal reward terhadap suatu aktivitas (Sutanto, 2015, h.51), orang yang melakukan aktivitas Tai Chi dengan benar akan merasakan penghargaan terhadap dirinya sendiri, serta memotivasi dirinya untuk menjadi lebih sehat dan memunculkan perilaku baru yang berfungsi untuk kesehatan. Melihat manfaat Tai Chi yang bisa membentuk perilaku sehat orang yang melakukannya, peneliti tertarik untuk melihat lebih jauh mengenai perilaku sehat yang dimiliki oleh orang yang melakukan olahraga Tai Chi.

\section{TINJAUAN PUSTAKA}

Menurut Sumaryono (Sutanto, 2015, h.ix) Tai Chi adalah sinergi dari olahraga, olah pikir, dan olah rasa. Tai Chi bila dilakukan secara teratur, maka akan mampu mendorong optimalisasi fungsi dari organ-organ tubuh yang pada waktunya dapat membantu tercapainya tingkat kesehatan tubuh secara total. Tai Chi merupakan gabungan gerakan fisik, meditasi, dan pernapasan untuk mendorong relaksasi dan ketenangan pikiran untuk meningkatkan keseimbangan, kontrol postural, koordinasi gerakan, daya tahan otot, kekuatan dan kelenturan (Setiabudhi dalam Sutanto, 2015, h.42).

Tai Chi termasuk dalam seni bela diri, yang mana seni bela diri dikembangkan untuk meningkatkan baik kebijaksanaan maupun keberanian (Ch'ing, 1985, h.9). Dalam philosofi China, Tai Chi melahirkan dua kekuatan kuno yaitu Yin dan Yang. Perkelahian disukai oleh orang-orang yang menggunakan kekerasan dalam seni bela diri, sedangkan Tai Chi menggunakan kelembutan yang bertujuan untuk menetralisir kekerasan. Langkah awal 
dalam mempelajari Tai Chi adalah menginvestasikan kekalahan, yang berarti membiarkan pihak lain menggunakan kekerasan untuk tidak menyerang, sementara anda tidak menggunakan kekuatan sedikitpun untuk mempertahankan diri, namun anda menuntun kekuatan lawan agar kekuatan itu menjadi tidak berguna, sehingga ketika anda menyerang siapapun lawannya akan terlempar jauh. Hal ini disebut dengan Tung Chi yang artinya memahami kekuatan. Tai Chi pertama kali diturunkan oleh Chang San-Feng melalui beberapa generasi. Penggunaan Tai Chi didasarkan pada prinsip Yin dan Yang, yang artinya kekerasan dan kelembutan saling menguasai.

Terdapat tingkatan yang berbeda dalam Tai Chi, di mana tingkatan tersebut dibagi menjadi tiga, yaitu: (a) tingkatan manusia yang bertujuan merelaksasikan atau mengendorkan otot serta mengaktifkan sel-sel darah (b) tingkatan bumi, membuka pintu gerbang sehingga Chi (air hawa murni atau tenaga yang sangat halus yang ada di dalam diri manusia dan dapat dihasilkan melalui latihan) dapat mencapai persendian (c) tingkatan surga yang bertujuan melatih panca indera. Dalam masing-masing tingkatan terdapat tiga tahapan mulai dari tahapan pertama yang paling rendah hingga ke tahapan ketiga yang paling tinggi.

Tai Chi sebagai latihan fisik dan mental dapat mengintegrasikan manfaat fisiologis dan psikologis. Manfaat fisiologis dari olahraga Tai Chi:

a. Menstimulasi otak.

b. Menjaga keseimbangan tekanan darah.

c. Membantu penyembuhan penyakit dyspnea, fibromyalgia, penyakit paruparu, dan gangguan kardiovaskular.

d. Pengurangan terhadap rasa nyeri.

e. Menambah kekuatan. f. Meningkatkan kualitas tidur. Manfaat psikologis dari olahraga

Tai Chi :

a. Meningkatkan motivasi hidup.

b. Memfasilitasi kebiasaan hidup yang sehat dan memunculkan perilaku sehat.

c. Menimbulkan perasaan tertarik untuk menjadi sehat.

d. Memperbaiki fungsi kognitif.

e. Mengurangi rasa stress.

Terdapat berbagai jenis olahraga yang dapat dilakukan seseorang sebagai bentuk perilaku sehat. Beberapa alasan yang melatarbelakangi seseorang melakukan olahraga Tai Chi menurut (Herdianto, 2015) adalah adanya kepercayaan bahwa olahraga Tai Chi dapat memperpanjang usia dan keinginan untuk meningkatkan kesehatan dan terhindar dari berbagai penyakit. Sedangkan menurut (Losyk, 2005, h.99) Tai Chi sebagai salah satu cara pengendalian stress dan relatif mudah dan dapat dilakukan siapa saja bahkan mereka yang duduk di kursi roda sehingga banyak orang memilih olahraga Tai Chi.

Perilaku sehat adalah perilaku yang dilakukan oleh seseorang untuk menstabilkan dan mengatur kesehatan mereka. Perilaku yang kurang sehat tidak hanya dapat menyebabkan penyakit tetapi juga dapat dengan mudah menjadi suatu kebiasaan yang tidak sehat. (Taylor, 2012, h.44). Menurut Renner and Schwarzer perilaku sehat juga didefinisikan sebagai perilaku seseorang yang terlibat dalam pemeliharaan atau peningkatan kesehatan mereka saat ini dan untuk menghindari penyakit. Termasuk beberapa perilaku untuk melindungi, mempromosikan, atau memelihara kesehatannya. Sedangkan Vickers mengungkapkan perilaku sehat secara luas dapat didefinisikan sebagai tindakan untuk mempertahankan atau meningkatkan kesehatan. (Rahmadian, 2011, h.14). 
Menurut Notoatmodjo (2005, h.46).perilaku sehat adalah suatu respon seseorang atau organisme terhadap stimulus yang berkaitan dengan sakit dan penyakit, system pelayanan kesehatan, makanan, serta lingkungan. Aktivitas pemeliharaan kesehatan tersebut dapat berupa perilaku yang dapat diamati (observable) maupun perilaku yang tidak dapat diamati (unobservable).

Menurut Vickers dalam Rahmadian (2011, h.15) terdapat empat kategori utama perilaku sehat yaitu: (a) perilaku yang mengurangi resiko membebani resiko adaptif tubuh, (b) perilaku yang melibatkan mengambil risiko, terutama sebagai pejalan kaki atau driver, (c) perilaku yang seharusnya membantu pencegahan timbulnya penyakit, dan (d) perilaku yang dapat meningkatkan kesehatan, tidak hanya pencegahan terhadap penyakit.

Vickers (Rahmadian, 2011, h.15) juga membagi perilaku sehat kedalam dua bagian dan empat komponen, yaitu:

a. Perilaku pencegahan: penjagaan, pengembangan, dan pemeliharaan kesehatan; serta pencegahan terjadinya kecelakaan.

b. Perilaku berisiko: risiko penggunaan zat, dan risiko dalam berlalu lintas.

Menurut Notoatmodjo (2005, h.47), perilaku orang yang sehat agar tetap sehat dan meningkat disebut dengan perilaku sehat (healthy behavior). Healthy behavior dibagi dalam dua bentuk perilaku yaitu perilaku preventif (tindakan atau upaya yang dilakukan untuk mencegah terjadinya sakit atau masalah kesehatan yang lainnya, misalnya kecelakaan), dan yang kedua adalah perilaku promotif (tindakan atau kegiatan untuk memelihara dan meningkatkan kesehatan) contoh dari perilaku promotif adalah makan makanan yang bergizi seimbang, tidak mengkonsumsi minuman atau makanan yang mengandung zat adiktif, istrahat yang cukup, rekreasi, dan melakukan olahraga secara teratur.

Menurut Becker (Notoatmodjo, 2005, h.47) kegiatan-kegiatan yang berkaitan dengan perilaku sehat, antara lain perilaku makan dengan menu seimbang dan bergizi, perilaku olahraga dengan melakukan kegiatan fisik secara teratur, perilaku istirahat dengan mengatur pola tidur yang cukup, perilaku mengendalikan dan manajemen stress yang baik, perilaku menaati peraturan yang berkaitan dengan lalu lintas, serta perilaku tidak mengkonsumsi minuman keras, rokok, dan obat-obatan terlarang.

Menurut Taylor (2012, h.45-47), faktor-faktor yang memengaruhi perilaku sehat adalah faktor demografi, usia, values, personal control, pengaruh sosial, personal goals, perceived symptoms, akses pelayanan kesehatan, dan faktor kognitif.

Tai Chi menjadi salah satu pilihan olahraga yang dilakukan sebagai bentuk upaya menjaga kesehatan, meskipun Tai Chi termasuk dalam seni bela diri. Tai Chi lahir dengan filosofi yang sangat kuat, sebagian orang menganggap seni bela diri adalah olahraga yang mengandung kekerasan dengan gerakan menantang dan mengandalkan kekuatan, namun tidak dengan Tai Chi. Tai Chi menggunakan gerakan-gerakan yang lembut dan lentur untuk menetralisir kekerasan.

Gerakan Tai Chi mempunyai filosofi yang bila dipahami dan dihayati, sambil melakukan gerakan tersebut, akan menjadi proses belajar kehidupan yang bermanfaat baik (Maramis dalam Sutanto, 2015, h.66). Orang yang melakukan olahraga Tai Chi dengan benar akan melakukan setiap gerakan dengan pemahaman filosofi yang benar pula, bahwa setiap gerakan bertujuan untuk membawa dirinya menjadi yang lebih baik 
dan lebih sehat. Proses belajar otak tentang kehidupan akan optimal apabila terjadi kesatuan antara motivasi dan niat, sensoris dan perasaan, pikiran (fokus termasuk pada filosofi nya) dan gerakan (Maramis dalam Sutanto, 2015, h.66).

Melihat berbagai macam manfaat dihasilkan dari olahraga Tai Chi, inilah yang menarik seseorang untuk mempraktekkan olahraga Tai Chi. Tai Chi tidak hanya mengubah kondisi fisik menjadi lebih sehat tetapi juga membawa seseorang kepada perubahan perilaku untuk menjadi lebih sehat. Menurut Wardy (Sutanto, 2015, h.51) orang yang melakukan Tai Chi dengan benar akan menghargai dirinya sendiri dan merasa bahwa Tai Chi merupakan latihan yang menimbulkan perasaan ketertarikan untuk menjadi sehat. Dalam jurnal yang berfokus pada penelitian mengenai efektivitas secara psikologis dari Tai Chi, dituliskan bahwa Tai Chi membawa perbaikan yang signifikan terhadap perilaku merawat tubuh dan perilaku sehat, dikarenakan adanya peningkatan motivasi (Zhang, Layne, Lowder, \& Liu, 2012, h.3) . Hal tersebut menunjukkan bahwa olahraga Tai Chi memiliki manfaat bagi munculnya perilaku sehat pada seseorang. Seperti pada subyek W yang mengaku bahwa ia mulai memperhatikan pola makan, pola istirahat, dan semakin mencintai olahraga semenjak ia rutin melakukan Tai Chi.

Tai chi sebagai seni bela diri dan olahraga juga berpengaruh terhadap kognitif seseorang. Manusia pada zaman sekarang sulit untuk menerima konsep yang diajarkan dalam Tai Chi karena manusia modern lebih menghendaki sesuatu yang cepat, instan, jelas dan teoritis. Pada latihan Tai Chi, yang diperlukan adalah ketenangan dengan memahami, meresapi, dan merasakan filosofi yang membangun Tai Chi, baik sebelum berlatih, saat berlatih, dan setelah berlatih. Latihan Tai Chi akan membawa kepada kondisi fokus dan mindfulness (keadaan di mana kesadaran yang dikehendaki, diterima, tidak judgemental, fokus pada pikiran,sensasi, dan emosi diri yang terjadi saat ini dari waktu ke waktu berjalan) (Maramis dalam Sutanto, 2015, h.74). Hal ini yang memberi manfaat pada fungsi kognitif orang yang melakukan olahraga Tai Chi, akan terjadi perbaikan fungsi eksekutif seperti konsentrasi dan perhatian. Fungsi kognitif yang baik menjadi salah satu faktor bagi munculnya perilaku sehat, karena menjadikan seseorang berpikir lebih baik mengenai pentingnya kesehatan bagi kehidupannya.

Melakukan olahraga Tai Chi dengan memahami filosofi dan manfaat yang terkandung di dalam nya akan membuat manusia menjadi sadar untuk lebih menghargai kehidupan dan menjadi lebih sehat. Orang yang memilki tujuan untuk menjadi lebih sehat dan menghargai kehidupannya dapat menjadi salah satu faktor munculnya perilaku sehat yaitu personal goals. Apabila seseorang memilki tujuan untuk menjadi sehat maka ia akan lebih giat dalam berolahraga dan melakukan upaya yang berkaitan dengan peningkatan ataupun pemeliharaan kesehatan.

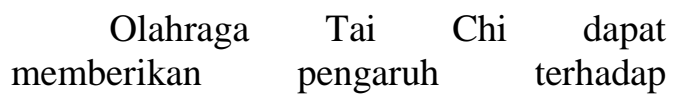
munculnya perilaku sehat pada seseorang. Tai Chi juga mempengaruhi beberapa faktor perilaku sehat. Faktor-faktor seperti personal goals dan faktor kognitif seseorang dapat memengaruhi munculnya perilaku sehat. Perilaku sehat yang muncul pada pelaku olahraga Tai Chi dapat dibagi ke dalam dua bentuk yaitu perilaku promotif dan perilaku pencegahan. Perilaku sehat yang muncul pada pelaku olahraga Tai Chi yaitu perilaku makan dengan menu seimbang 
dan bergizi, perilaku olahraga dengan melakukan kegiatan fisik secara teratur, perilaku istirahat dengan mengatur pola tidur yang cukup, perilaku mengendalikan dan manajemen stress yang baik, perilaku menaati peraturan yang berkaitan dengan lalu lintas, serta perilaku tidak mengkonsumsi minuman keras, rokok, dan obat-obatan terlarang.

\section{METODE}

Penelitian tentang perilaku sehat pelaku olahraga Tai Chi menggunakan metode penelitian kualitatif yang dilakukan melalui proses wawancara dan observasi. Penelitian ini dilakukan di kota Semarang, Jawa Tengah dengan jumlah subjek tiga orang dengan pendekatan purposive sampling. Kriteria yang digunakan untuk menentukan subyek pada penelitian ini adalah orang yang melakukan olahraga Tai Chi minimal selama 3 tahun.

\section{HASIL DAN PEMBAHASAN}

Subjek I, II, dan III memiliki alasan masing-masing yang melatarbelakangi mereka melakukan olahraga Tai Chi. Kesamaan alasan yang melatarbelakangi ketiga subjek melakukan olahraga Tai Chi adalah adanya keinginan untuk menjadi sehat. Kesehatan memang hal yang dianggap sangat penting dalam kehidupan ketiga subjek. Subjek I memiliki riwayat kesehatan yang kurang baik, karena pola hidup yang tidak sehat di masa muda, subjek I terserang penyakit stroke pada usia 54 tahun yang membuat subjek lumpuh dan tidak bisa menggerakkan sebagian tubuhnya. Subjek I mengatakan bahwa alasannya melakukan olahraga Tai Chi adalah untuk mendapatkan kesembuhan dari penyakit stroke yang diderita. Subjek II juga mengatakan bahwa olahraga Tai Chi dilakukan untuk terhindar dari berbagai jenis penyakit serta keinginan untuk memiliki umur yang panjang. Selain untuk menjaga kesehatan, latar belakang subjek III melakukan olahraga Tai Chi adalah sebagai refreshing atau penyegaran, karena olahraga Tai Chi dapat memberikan ketenangan batin di saat subjek III merasa suntuk.

Olahraga Tai Chi yang dilakukan oleh ketiga subjek hampir sama yaitu melakukan beberapa jurus Tai Chi dan dalam setiap olahraga Tai Chi dilakukan sekitar 30 sampai 40 menit. Dalam olahraga Tai Chi terdapat beberapa jurus, yang menurut ketiga subjek, jurus-jurus ini memiliki inti yang sama dan gerakannya saja yang divariasi. Subjek III yang melakukan Tai Chi Sekitar 13 tahun menguasai jurus yang lebih seikit dibandingkan dengan subjek I dan subjek II yang sudah 23 tahun melakukan olahraga Tai Chi. Subjek I dan subjek II mampu melakukan jurus Tai Chi dengan berlawanan arah, serta memadukan gerakan Tai Chi dengan peralatan seperti pedang dan kipas.

Faktor-faktor yang mempengaruhi ketiga subjek memiliki perilaku sehat, hampir sama yaitu adanya pengaruh sosial, personal goals, dan faktor kognitif. Subjek I dan subjek II belajar Tai Chi dari sumber yang sama, mereka mengatakan bahwa komunitas Tai Chi yang mereka kenal memberikan pengaruh positif dalam hal menjaga kesehatan. Subjek II yang juga memiliki kelompok olahraga seperti kelompok pejalan kaki dan pesepeda yang menurut subjek II adalah orang-orang yang sadar akan kesehatan. Subjek III juga mengatakan bahwa perilaku sehat yang dimilikinya dipengaruhi oleh lingkungan sosial. Subjek III mengenal olahraga Tai Chi dari paman yang juga mengajarkan banyak hal mengenai filosofi Tai Chi, selain itu subjek III juga pernah ikut dan tergabung dalam komunitas Tai Chi dan 
dari komunitas tersebut subjek mengenal banyak orang yang peduli dengan kesehatan. Subjek I juga mengatakan mendapat dukungan yang besar dari teman-teman dan keluarga terutama pada masa pemulihannya dulu, dan setelah pulihpun orang-orang di sekitar tetap memberi pengaruh yang positif bagi subjek I dalam menjaga kesehatan.

Masing-masing subjek juga memiliki tujuan atau personal goals yang menjadikan subjek berperilaku sehat (Taylor, 2012, h.45-47). Subjek I mempunyai tujuan untuk menghabiskan sisa hidupnya dengan bahagia bersama keluarga, subjek II punya tujuan bisa terus menemani keluarga, melihat semua anaknya menikah, dan menimang cucu. Sedangkan subjek III memiliki tujuan menjadi teladan bagi anak-anak subjek III agar peduli terhadap kesehatan. Bagi ketiga subjek, tujuan mereka masingmasing dapat terwujud apabila mereka memiliki kesehatan yang baik, dan hal ini yang memuncukan perilaku sehat pada subjek.

Faktor kognitif juga berpengaruh terhadap perilaku sehat subjek (Taylor, 2012, h.45-47). Faktor kognitif berkaitan dengan keyakinan subjek terhadap perilaku sehat tertentu. Ketiga subjek memiliki pemikiran yang tepat dan mempunyai keyakinan bahwa Tai Chi telah membawa mereka pada kesadaran untuk menghargai dan mencintai kehidupan. Subjek II dan subjek III sependapat bahwa Tai Chi mengubah mind set dan pikiran menjadi jernih, hal ini menjadikan subjek lebih peduli dan melakukan usaha untuk menjaga kesehatan sebagai bentuk penghargaan terhadap kehidupan. Subjek I yang awalnya tidak mengenal olahraga Tai Chi, tidak menyadari pentingnya menerapkan pola hidup sehat hingga akhirnya subjek I jatuh sakit. Setelah melakukan olahraga
Tai Chi ketiga subjek menjadi lebih sadar akan pentingnya berperilaku sehat dan menghindari perilaku yang berisiko memunculkan gangguan kesehatan.

Selain itu ada juga faktor yang di luar olahraga Tai Chi yang mempengaruhi perilaku sehat pada subjek. Pada subjek I, peneliti menemukan adanya perceived symptoms atau gejala gangguan kesehatan tertentu berupa penyakit stroke yang membuat subjek I terdorong untuk melakukan perilaku sehat. Sedangkan pada subjek III, peneliti menemukan bahwa faktor usia menjadi salah satu faktor yang berpengaruh pada perilaku sehat subjek. Subjek III menegaskan bahwa subjek III memiliki kekhawatiran di usianya yang sudah lebih dari 30 tahun sudah mulai rentan terserang penyakit atau gangguan kesehatan lainnya.

Perilaku sehat yang ditunjukkan oleh masing-masing subjek cukup beragam terutama pada perilaku makan. Ketiga subjek menunjukkan pola makan yang teratur dan baik, seperti menghindari makanan yang mengandung bahan kimia, bahan pengawet, makanan manis dan makanan instan. Subjek I dan subjek II masih memakan daging namun dalam jumlah yang sedikit, karena daging atau makanan berlemak dapat memicu timbulnya masalah kesehatan. Berbeda dengan subjek III yang menerapkan pola makan vegan, atau pola makan yang tidak menkonsumsi daging, meskipun masih menkonsumsi produk turunannya seperti telur, susu, dan keju. Subjek III yang sama sekali tidak memakan daging merah mengatakan bahwa perilaku ini sebagai bentuk dia mencintai hidup dan juga menerapkan ajaran Budha. Ketiga subjek juga menkonsumsi buah, sayur, dan air mineral dalam porsi yang cukup. Subjek I memiliki kebiasaan melakukan terapi urin atau yang dikenal dengan istilah urotherapy. Subjek I meminum segelas 
urin nya sendiri di pagi hari, dan haruslah urin yang baru dikeluarkan setelah bangun pagi. Subjek I mengatakan bahwa dengan melakukan terapi urin ia merasa lebih sehat. Peneliti mencoba mencari informasi mengenai manfaat dari urotherapy, dan ternyata memang terapi ini bermanfaat dalam menjaga kesehatan. Kandungan antibakteri dan antijamur pada urin dapat meningkatkan kekebalan tubuh dari penyakit (Kompas, 2015). Selain melakukan terapi urin, subjek juga senang meminum jamu. Subjek II memiliki kebiasaan meminum infused water yang dipercaya subjek dapat menambah kesehatan. Infused water adalah minuman yang terbuat dari air mineral yang diberi potongan buah dan kemudian direndam selama kurang lebih dua jam. Penelitian selama ini tidak menunjukkan adanya khasiat yang besar dari meminum infused water, namun tidak berarti infused tidak baik bagi kesehatan hanya saja akan lebih besar khasiatnya apabila buah dimakan secara langsung atau di jus ketimbang direndam dalam air (Lubis, 2014).

Ketiga subjek juga menunjukkan perilaku sehat yaitu berupa latihan fisik atau olahraga. Subjek I memiliki kegiatan olahraga yaitu melatih Tai Chi setiap hari, sedangkan subjek II melakukan olahraga Tai Chi dua kali seminggu dan melakukan olahraga senam setiap pagi. Subjek III juga melakukan olahraga Tai Chi secara rutin yaitu dua kali seminggu dan olahraga berenang satu atau dua kali dalam seminggu. Olahraga Tai Chi yang dilakukan ketiga subjek memberi peranan penting dalam perilaku sehat subjek (Zhang, Layne, Lowder, \& Liu, 2012, h.3). Ketiga subjek sependapat bahwa olahraga Tai Chi berbeda dengan olaraga yang lain. Subjek I dan subjek II memiliki pendapat bahwa olahraga Tai Chi adalah olahraga yang paling baik karena tidak hanya menyehatkan secara fisik tetapi juga memberikan ajaran tentang kebaikan, mencintai kehidupan, dan ajaran yang berkaitan dengan kesehatan. Subjek III juga mengatakan bahwa olahraga Tai Chi menyadarkan subjek untuk lebih peduli dengan kesehatan.

Ketiga subjek juga memiliki pola tidur yang berbeda-beda. Subjek I dan subjek III memiliki waktu istirahat yang cukup sekitar tujuh dan delapan jam sehari. Sedangkan subjek II memiliki jam istirahat yang hanya sekitar lima hingga enam jam dalam sehari. Menurut informasi yang didapatkan peneliti dari CNN Indonesia, jam istirahat tidak bisa diberlakukan sama antara satu orang dengan lainnya (Setyanti, 2015). Bukan jam tidur yang menjadi patokan tetapi lebih pada kualitas tidur sehingga apabila subjek II hanya tidur lima atau enam jam sehari, namun subjek II meras cukup dan bangun dengan segar di pagi hari berarti subjek II sudah memiliki pola tidur yang baik.

Mengenai manajemen stres, ketiga subjek memiliki pengendalian stres yang cukup baik. Subjek I menjelaskan bahwa menghadapi permasalahan seperti menghadapi lawan dalam Tai Chi, subjek berusaha untuk tenang dan tidak menggunakan emosi sehingga tidak muncul permasalahan baru. Subjek I mengandalkan Tuhan dalam menghadapi permasalahan kehidupan. Subjek II juga sependapat bahwa dalam mengendalikan stres subjek II memilih untuk tenang dan berpikiran positif. Subjek II mengatakan bahwa setiap orang pasti punya permasalahan sehingga dalam menghadapinya tidak perlu stress. Subjek III mengaku setelah mengenal olahraga Tai Chi dirinya menjadi orang yang lebih sabar dan tenang dalam menghadapi apapun. Subjek III menjadikan keluarga sebagai tempat menghibur diri apabila mengalami suatu permasalahan. Ketiga 
subjek memiliki manajemen stres yang baik, dan menyikapi suatu permasalahan secara tenang.

Secara umum ketiga subjek memiliki ketaatan terhadap peraturan yang berkaitan dengan lalu lintas. Subjek I dan subjek III menunjukkan menjaga keamanan saat berkendara dengan menggunakan perlengkapan seperti helm dan sabuk pengaman. Subjek II yang lebih sering menggunakan sopir pribadi, memilih sopir yang berhati-hati dalam berkendara sehingga dapat terhindar dari bahaya saat di jalan raya.

Subjek II mengatakan bahwa dalam Tai Chi diajarkan untuk mencintai tubuh, dan hal ini diwujudkan oleh ketiga subjek dengan tidak memasukkan racun atau zatzat berbahaya ke dalam tubuh yang dapat menimbulkan permasalahan kesehatan. Subjek I yang dulu menkonsumsi rokok dan minuman keras, setelah mengenal olahraga Tai Chi sudah tidak lagi menkonsumsi rokok dan minuman keras. Subjek III juga menghindari konsumsi rokok, minuman keras, apalagi obatobatan terlarang, meskipun demikian subjek tidak bisa terbebas seratus persen dari asap rokok karena masih banyak orang di sekitar subjek yang merokok.

\section{SIMPULAN DAN SARAN simpulan}

Berdasarkan latar belakang masalah, telaah teori, hasil analisis data, dan pembahasan yang telah dilakukan terhadap penelitian, makan dapat disimpulkan pelaku olahraga Tai Chi memiliki perilaku sehat. Perilaku sehat yang diteliti adalah perilaku sehat menurut Becker (Notoatmodjo, 2005, h.47), yaitu perilaku sehat melalui pola makan dengan menu seimbang dan bergizi, melakukan kegiatan fisik atau olahraga secara teratur, istirahat yang cukup, mengendalikan dan manajemen stress yang baik, menaati peraturan yang berkaitan dengan lalu lintas, serta tidak mengkonsumsi minuman keras, rokok, dan obat-obatan terlarang.

Ketiga subjek memiliki perilaku sehat tersebut, dan olahraga Tai Chi menjadi faktor pendorong yang kuat dalam perilaku sehat yang dimiliki oleh ketiga subjek. Perilaku sehat yang dimiliki oleh masing-masing subjek tergolong dalam perilaku promotif dan perilaku preventif, sesuai dengan latar belakang masing-masing subjek dalam melakukan perilaku sehat tersebut.

\section{Saran}

Berdasarkan hasil penelitian yang diperoleh, maka peneliti mengajukan beberapa saran sehubungan dengan hasil penelitian, sebagai berikut :

1. Bagi pelaku olahraga Tai Chi. Saran untuk pelaku olahraga Tai Chi, agar terus mempertahankan perilaku sehat yang sudah dimiliki dan mengasah terus kemampuan olahraga Tai Chi sehingga semakin meningkatkan kesehatan.

2. Bagi masyarakat luas. Kesibukan dan banyaknya kegiatan tidak seharusnya menjadikan masyarakat lupa untuk menjaga kesehatan. Masyarakat diharapkan memiliki kesadaran akan pentingnya mencintai kehidupan dengan belajar membiasakan diri menerapkan perilaku-perilaku sehat seperti yang dimiliki oleh pelaku olahraga Tai Chi.

3. Bagi peneliti selanjutnya. Peneliti selanjutnya jika akan meneliti topik yang sama dimohon melakukan observasi secara lebih detail, sehingga perilaku yang diteliti tidak hanya berdasarkan hasil wawancara tetapi juga nampak secara nyata. 


\section{DAFTAR PUSTAKA}

Arora, R. (2015, July 4). Which one is better Wingchun, Wushu or Taichi? Retrieved October 18, 2016, from Quora: https://www.quora.com/Whichone-is-better-Wingchun-Wushuor-Taichi

Ch'ing, C. M. (1985). Cheng Tzu's Thirteen Treatises on T'ai Chi Ch'uan. California: North Atlantic Books.

Depkes, R. (2009). Undang-Undang Kesehatan. Jakarta: Indonesia Legal Center Pubishing.

Ekowarni, E. (2001). Pola Perilaku Sehat dan Model Pelayanan Kesehatan Remaja. Jurnal Psikologi, 2, 97104.

Herdianto, R. (2015, November 18). Sehat A-Z. Retrieved April 27, 2016, from 1Health: http://www.1health.id/id/article/ca tegory/sehat-a-z/meski-terlihatsama-ini-perbedaan-yoga-pilatesdan-tai-chi.html

Kemenkes, R. (2013). Buletin Jendela Data dan Informasi Kesehatan. Jakarta: Pusat Data dan Informasi Kementerian Kesehatan RI.

Kompas. (2010, July 26). Kompas.com. Retrieved October 16, 2015, from Health: http://health.kompas.com/read/20 10/07/26/13482457/beda.obesitas. dan.overweight

Kompas. (2015, January 20). Terapi Urine Baik untuk Kesehatan Kulit? Retrieved August 22, 2016, from Kompas Health: http://health.kompas.com/read/20 15/01/20/163000723/Terapi.Urine .Baik.untuk.Kesehatan.Kulit.

Losyk, B. (2005). Kendalikan Stres Anda. Jakarta: Gramedia Pustaka Utama.

Lubis, R. (2014, June 09). Seminar Kesehatan Gizi "Infused Water, Gaya Sehat Minum Air". Retrieved August 22, 2016, from FKMUSU:

http://fkm.usu.ac.id/content/index/ 4/id_cnt_berita_child?id=14

Notoatmodjo, S. (2005). Promosi Kesehatan. Jakarta: Rineka Cipta.

Rahmadian, S. (2011). Faktor Faktor Psikologis yang Memengaruhi Perilaku Sehat Mahasiswa Beberapa Perguruan Tinggi di Tangerang Selatan. Jakarta: Universitas Islam Negeri Syarif Hidayatullah.

Setyanti, C. A. (2015, October 13). Waktu Tidur dan Bangun Tidur yang Paling Tepat Setiap Hari. Retrieved August 22, 2016, from CNN Indonesia: http://m.cnnindonesia.com/gayahidup/20151012181033-25584511/waktu-tidur-dan-bangun- 
tidur-yang-paling-tepat-setiaphari/

Sutanto, J. (2015). Tai Chi dan Kesehatan Otak. Jakarta: PT Kompas Media Nusantara.

Taylor, S. E. (2012). Health Psychology. Los Angeles: McGraw-Hill.

WHO. (2014). Global Status Report of Noncommunicable Diseases. Geneva: World Health Organization.

Zhang, L., Layne, C., Lowder, T., \& Liu, J. (2012). A Review Focused on the Psychological Effectiveness of TaiChi on Different Populations. Evidence-Based Complementary and Alternative Medicine, 2012, $1-9$. 